\title{
3D numerical prediction of failure behaviour for the straight and curved parts of retaining wall according to various heights
}

\author{
Suk-Min Kong ${ }^{1}$, Jong-Hyun Lee ${ }^{1}$, Hyuk-Sang Jung ${ }^{2}$ and Yong-Joo Lee ${ }^{\text {* }^{*}}$
}

*Correspondence:
ucesyjl@seoultech.ac.kr
${ }^{1}$ Department of Civil
Engineering, Seoul National
University of Science
and Technology, 232
Gongneung-ro, Nowon-gu,
Seoul 139-743, South Korea
Full list of author information
is available at the end of the
article

${ }^{*}$ Correspondence: ucesyjl@seoultech.ac.kr Engineering, Seoul National University of Science and Technology, 232 Gongneung-ro, Nowon-gu, article

\begin{abstract}
Reinforced soil retaining walls are widely used for road and railway construction, various types of embankment, housing and industrial development, etc. with good safety and economic efficiency, and the number of studies on reinforced soil retaining walls has steadily increased. However, most research on reinforced soil retaining walls focus on two-dimensional linear parts. The behaviour of curved parts in reinforced soil retaining wall is questionable, and collapse of that also occurs frequently. Therefore, in this study, reinforced soil retaining walls were modelled by stacking blocks of $0.4 \times 0.5 \times 0.4 \mathrm{~m}$ (length $\times$ width $\times$ height), and the retaining walls were divided into four cases (heights of 3.2, 5.2, 7.2, 9.2 m). The failure behavior of the straight parts and the curved parts were compared, depending on the height. Based on the height of the reinforced soil retaining wall, the failure behaviours of the curved parts and straight parts of the reinforced soil retaining wall were predicted through 3D numerical analysis. This study aims to raise the necessity of research on the curved parts.
\end{abstract}

Keywords: Reinforced soil retaining wall, Height, Straight parts, Curved parts, Failure behaviour, 3D numerical

\section{Introduction}

A reinforced soil retaining wall is a structure that suppresses displacement of the soil by horizontal insertion of a reinforcing material having a large tensile force and frictional force, such as a metal band, a metal rod, and a geotextile on a back fill. It is economical and has been widely used [6]. Generally, the reinforcing soil retaining wall needs to be $5 \mathrm{~m}$ high or more, and the economic efficiency of the retaining wall improves as the retaining wall height increases (about $9 \mathrm{~m}$ or more). In this study, blocks of $0.4 \times 0.5 \times 0.4 \mathrm{~m}$ (length $\times$ width $\times$ height) were stacked. Failure behaviours were predicted according to heights of 3.2, 5.2, 7.2, and $9.2 \mathrm{~m}$, as shown in Table 1.

The collapse form of the reinforced soil retaining wall can be divided into external and internal factors, as shown in Figs. 1 and 2. The factors of extrinsic destruction are base sliding, overturning, and bearing capacity. The factors of internal destruction are tensile overstress, pull-out, internal sliding, bulging, connection failure, local overturning, and crest toppling. The collapse of these various reinforced soil retaining walls has been reported in Korea. Figure 3 shows a case in which the front wall has fallen because of 
Table 1 Cases of various heights

\begin{tabular}{llc}
\hline Case & Height $(\mathrm{m})$ & $\begin{array}{c}\text { Geogrid } \\
\text { layer (EA) }\end{array}$ \\
\hline 1 & 3.2 & 7 \\
2 & 5.2 & 12 \\
3 & 7.2 & 17 \\
4 & 9.2 & 22 \\
\hline
\end{tabular}

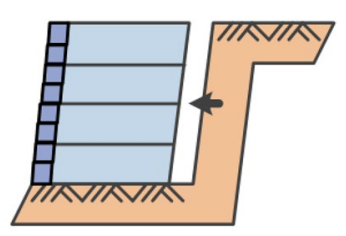

a Base sliding

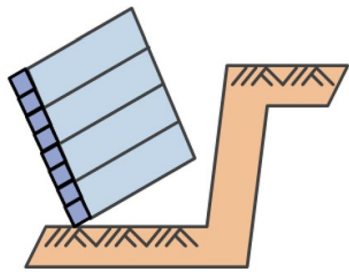

b overturning

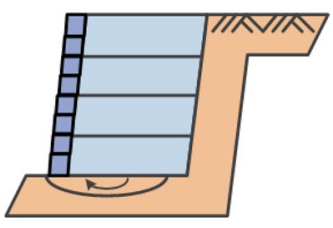

c Bearing capacity

Fig. 1 External factors of collapse

insufficient treatment of the upper road surface water for the reinforcing soil retaining wall, improper installation of the uppermost reinforcing material, or a defective connection state between the front wall and the reinforcing material [9]. Many other causes of collapse, such as wall subsidence, cracks, and deformation, have been reported (Fig. 4).

\section{Literature review}

Because of the population density and the characteristics of the Korean domestic topography, reinforced soil retaining walls have been frequently used for expanding sites. In addition, the reinforced soil retaining walls have such advantages as economy and workability. As a result, the reinforced soil retaining wall market has rapidly grown. However, unreliable design and construction resulting from price competition among companies have caused collapse accidents of reinforced soil retaining wall to occur frequently [7]. Therefore, various studies have been reported for safer construction of reinforced soil retaining walls.

Recently, more research on 3D numerical analysis has become necessary because interest in the destruction of the curved parts of reinforced soil retaining walls is increasing. $\mathrm{Ki}$ et al. [5] analysed the behaviour by the form (convex, concave) of the reinforced soil retaining wall through an model test. In this study, the maximum horizontal displacement occurred at the centre both of concave and convex curves. In the case of the convex type, as opposed to the concave type, large horizontal displacement occurred due to earth pressure. Jung [4] analysed the behaviour of the reinforced soil retaining wall 


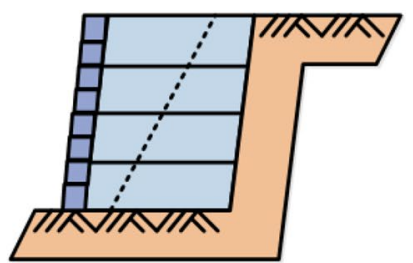

a Tensile overstress

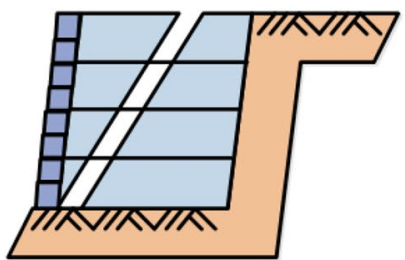

b Pull out

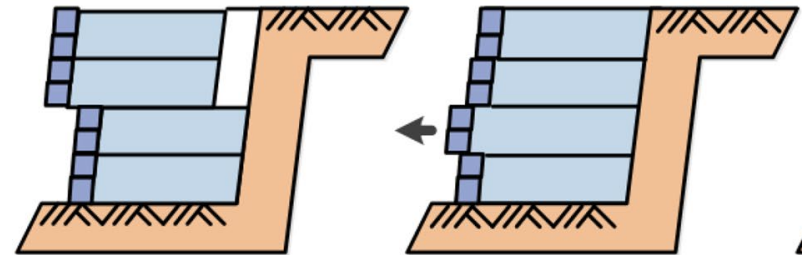

d Bulging

c Internal sliding

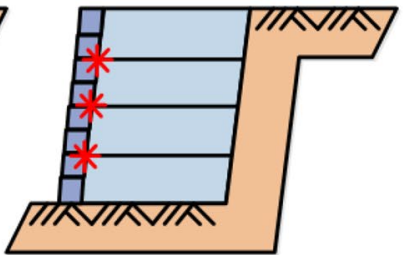

e Connection failure

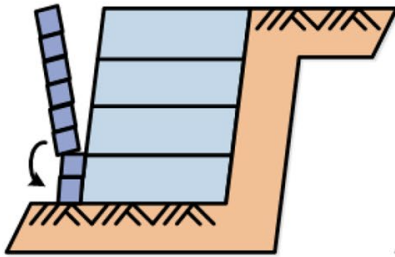

f Local overturning

Fig. 2 Internal factors of collapse

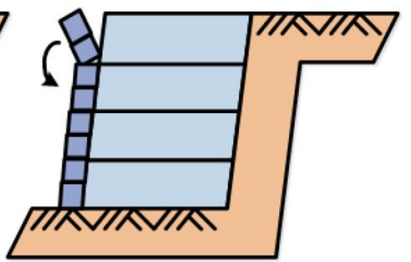

g Crest toppling

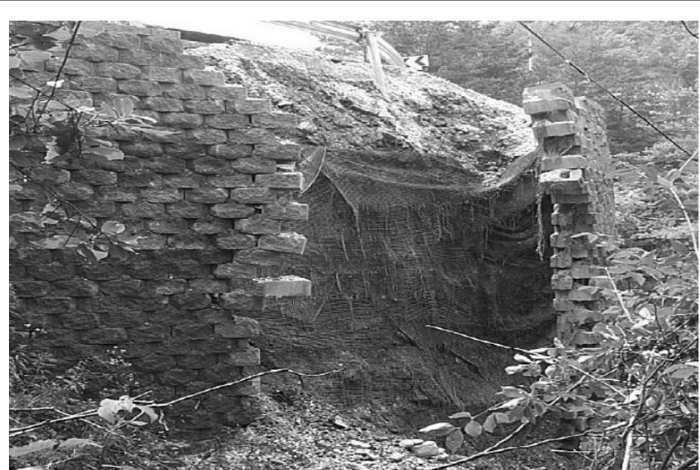

Fig. 3 Bulging and collapse [9]

based on the surface load and relative density using 3D numerical analysis. Oh et al. [11] determined the behaviour characteristics of the reinforced soil retaining wall according to the curvature of the curved parts of the retaining wall, and they predicted the optimal curvature by numerical analysis. Also, many studies have been carried out on the reinforcing materials used for reinforced soil retaining walls [1, 14]. Lee et al. [8] studied the behaviour of the ground according to the length and spacing of the geogrid through model testing and numerical analysis. The ground surface settlement caused by artificial destruction was measured using the device used for the model test. 


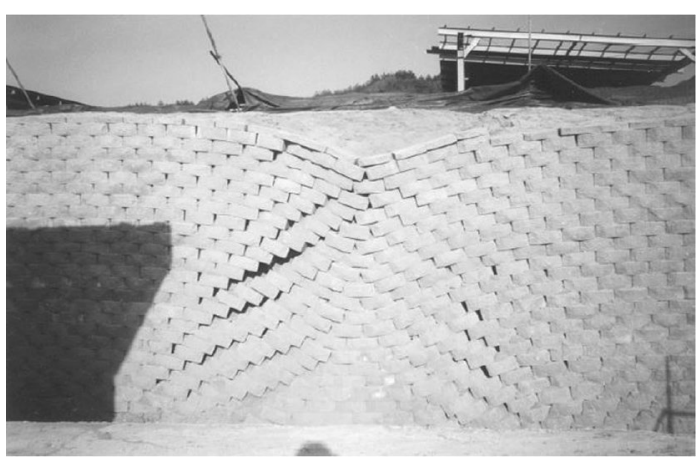

Fig. 4 Settlement and deformation of retaining wall [9]

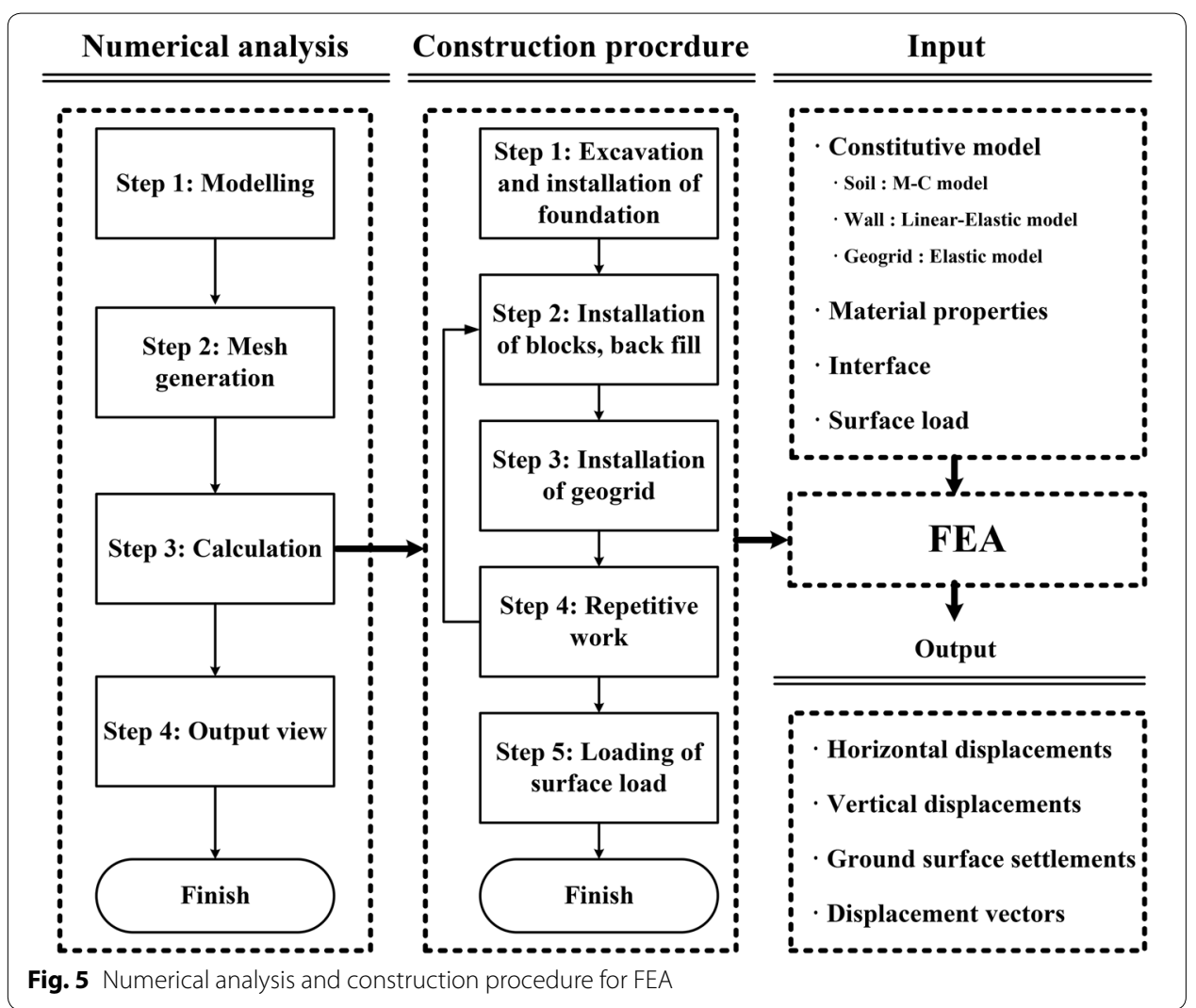

In this study, the behaviours of the wall and the surrounding ground were compared and analysed according to various reinforced soil retaining walls (from a height of $3.2 \mathrm{~m}$, which is lower than the height of the minimum reinforced soil retaining wall, to a retaining wall of $9 \mathrm{~m}$ or more, which is superior in economy) (Choi and Park [2]). 3D numerical analysis was used to compare the failure of the straight parts and the curved parts of the reinforced soil retaining wall. 


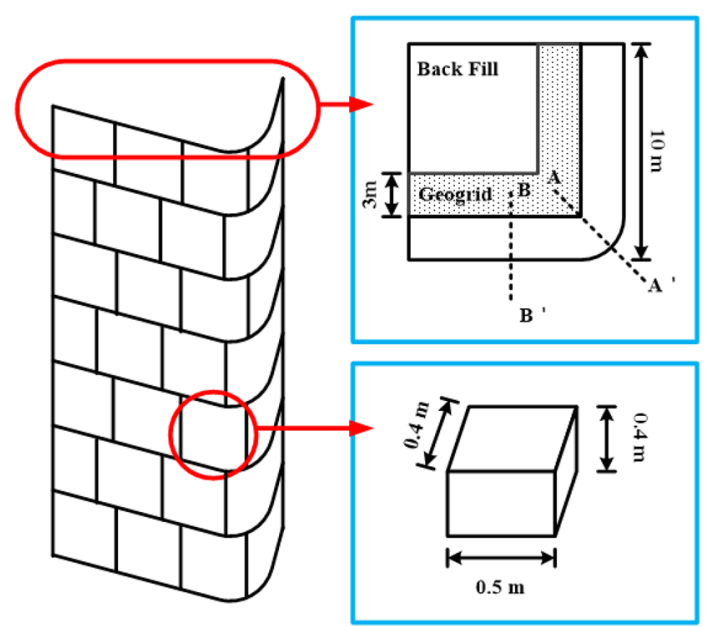

Fig. 6 Modelling detail

$\mathbf{a}$

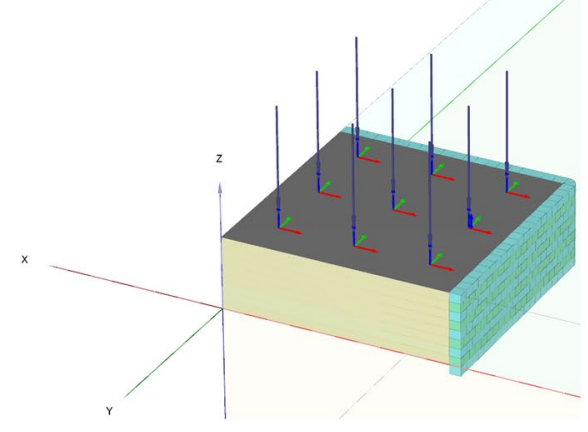

c

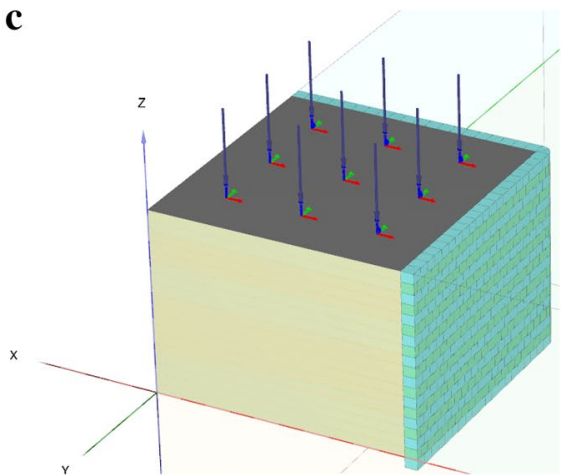

b

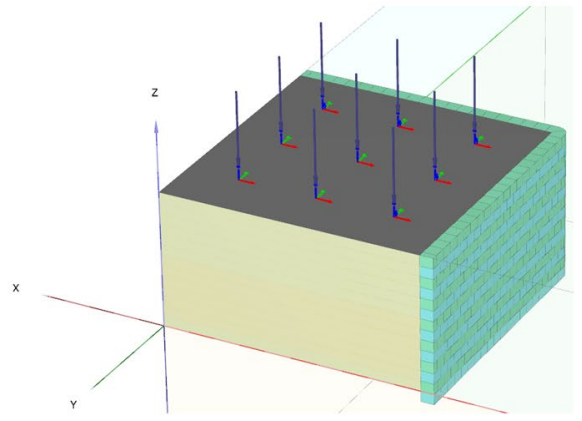

d

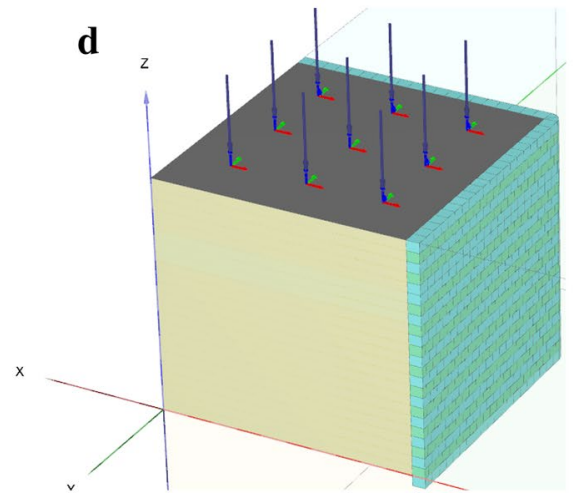

Fig. 7 Modelling according to four cases: a CASE 1; b CASE 2; c CASE 3; d CASE 4

\section{Numerical analysis}

In this research, PLAXIS 3D, which is a numerical analysis program, was used to compare the straight parts and the curved parts of the reinforced soil retaining wall [13]. 
Table 2 Material parameters in finite-element analysis

\begin{tabular}{llll}
\hline Parameter & Original ground & Back fill & Wall \\
\hline$Y\left(\mathrm{kN} / \mathrm{m}^{3}\right)$ & 20 & 15.88 & 23 \\
$\mathrm{E}\left(\mathrm{kN} / \mathrm{m}^{2}\right)$ & 300,000 & 40,000 & 18,420 \\
$V$ & 0.33 & 0.3 & 0.1 \\
$\mathrm{C}\left(\mathrm{kN} / \mathrm{m}^{2}\right)$ & 50 & 5 & - \\
$\Phi\left({ }^{\circ}\right)$ & 35 & 35 & - \\
\hline
\end{tabular}

$\gamma$, unit weight of soil; E: Young's modulus; $v$, Poisson's ratio, $c$, Cohesion; $\Phi^{\prime}$, angle of shearing resistance

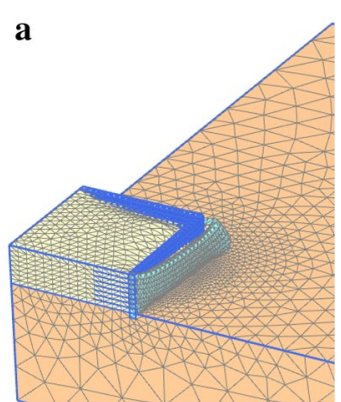

c

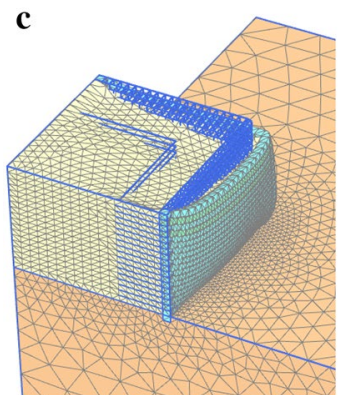

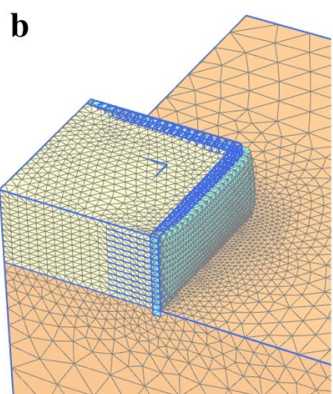

d

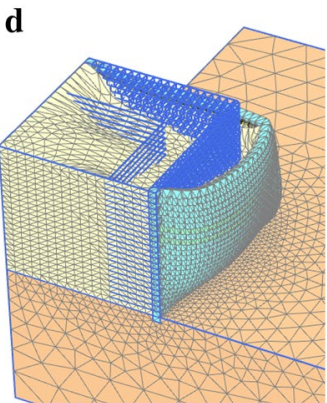

Fig. 8 Deformed meshes: a CASE 1; b CASE 2; c CASE 3; d CASE 4

\section{Modelling}

The procedure of numerical analysis and construction is shown in Fig. 5. A block of $0.4 \times 0.5 \times 0.4 \mathrm{~m}$ (length $\times$ width $\times$ height) was piled up, and a wall $10 \mathrm{~m}$ in width and $10 \mathrm{~m}$ in length was modelled (Fig. 6). Figure 7 is modelling according to four cases. Based on the work of Kwon et al. [6], the embedded depth of the wall was set to $0.4 \mathrm{~m}$. The height of the wall was divided into four cases $(3.2,5.2,7.2$, and $9.2 \mathrm{~m})$. The number of layers corresponding to the height of each reinforced soil retaining wall is shown in Table 1. In addition, a load of $100 \mathrm{kN}$ was applied to the ground surface of the back fill and upper walls with reference to the existing literature 


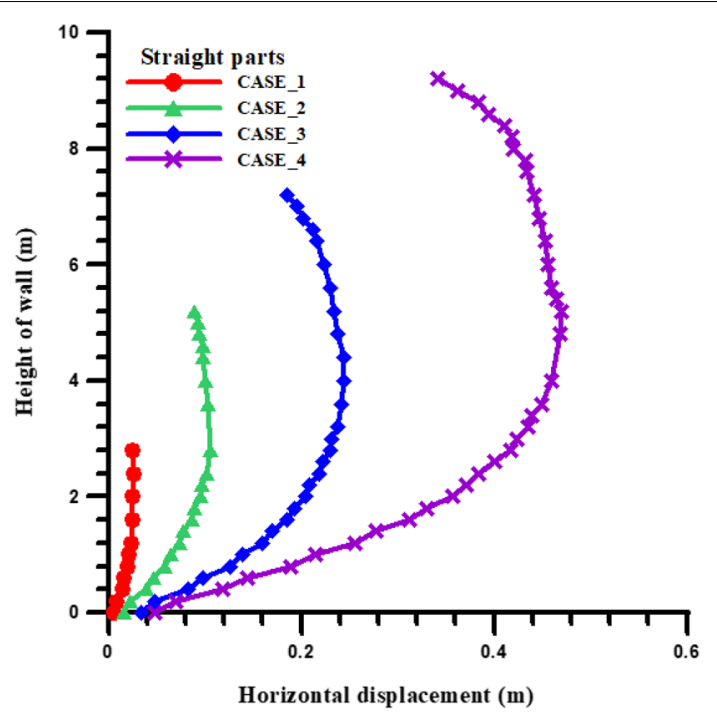

Fig. 9 Horizontal displacements for straight parts

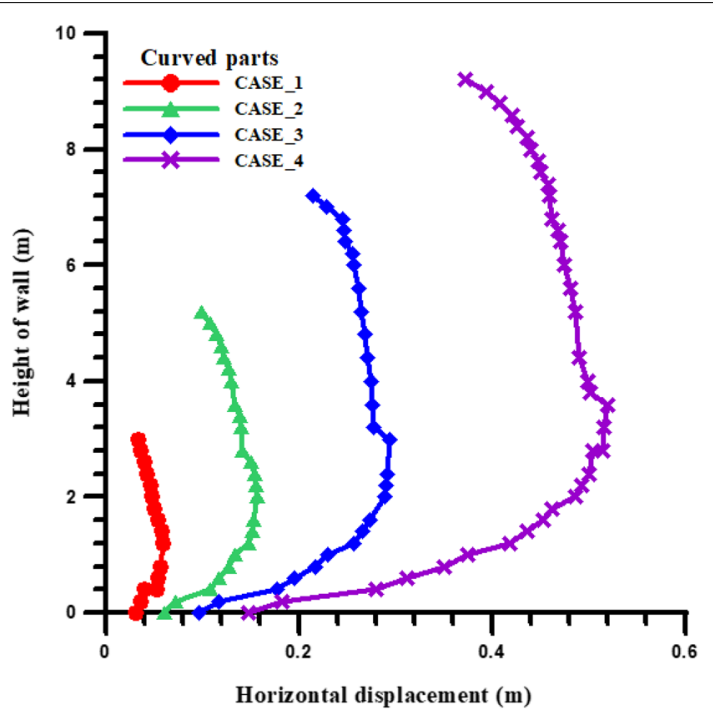

Fig. 10 Horizontal displacements for curved parts

\section{Material parameters}

The Mohr-Coulomb model (associated flow rule) was applied to the original ground and back fill and the linear-elastic model to the wall. The interface of the back fill between and the walls was 0.8 . The compaction of the back fill was determined to be dense soil with a relative density of $80 \%$ based on the work of Das [3]. A geogrid was installed every $0.4 \mathrm{~m}$ (one layer), and EA of $50 \mathrm{kN} / \mathrm{m}$ was applied [15]. Table 2 shows the material parameters of the original ground, back fill, and wall by referring to the existing literature (Lee et al. [10], Patki et al. [12]). 


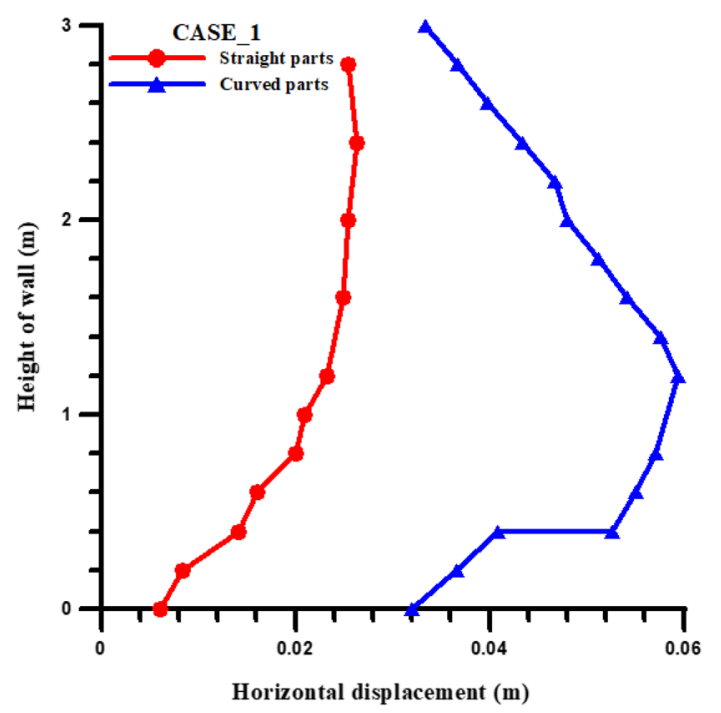

Fig. 11 Horizontal displacement comparison of straight and curved parts for Case 1

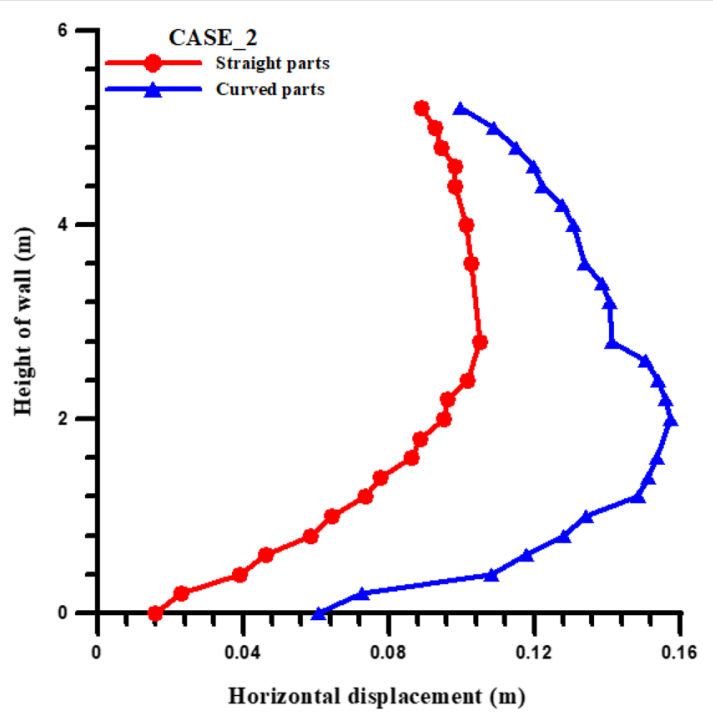

Fig. 12 Horizontal displacement comparison of straight and curved parts for Case 2

\section{Results}

\section{Deformed mesh}

Figure 8 shows the deformed mesh of the 3D numerical analysis. It is possible to confirm the displacement occurring on the wall as a result of the back fill and the surface load. The displacement of the wall increases as the height of the reinforced soil retaining wall increases.

\section{Horizontal displacements}

Figures 9 and 10 show the horizontal displacement of the curved parts and the straight parts according to the height of the reinforcing soil retaining wall. Case 1 


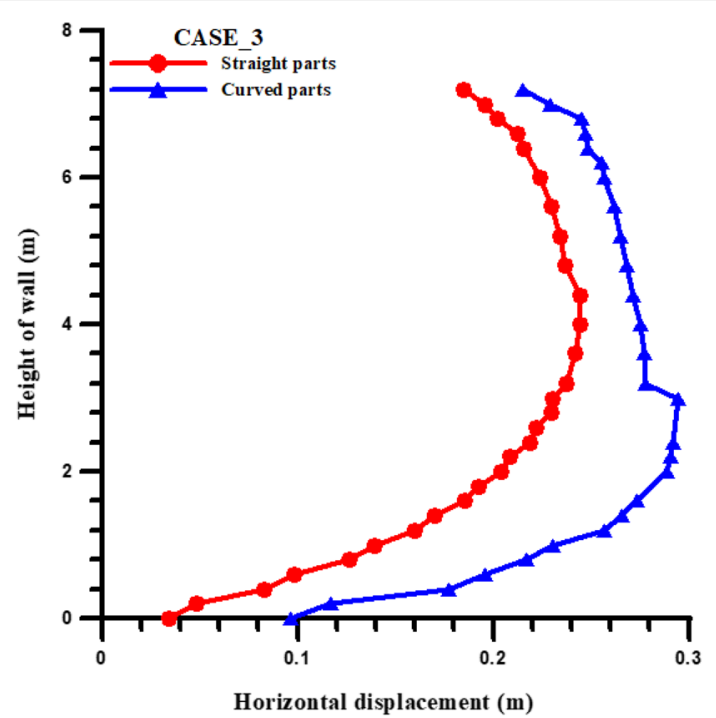

Fig. 13 Horizontal displacement comparison of straight and curved parts for Case 3

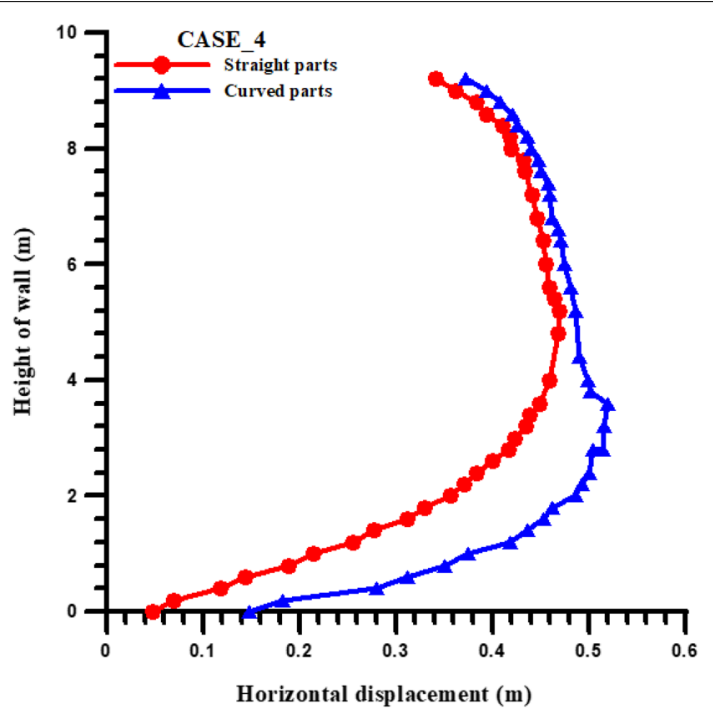

Fig. 14 Horizontal displacement comparison of straight and curved parts for Case 4

with the lowest height shows the least bulging in the straight parts. However, the higher the height, the more bulging increases sharply (Fig. 8). The Case 1 ratio to Case 2, Case 3, and Case 4 increased 4.1, 9.7, and 18.8 times at the $H / 2$ points of the straight part of the wall, and horizontal displacements increased 4.1, 9.7, and 18.8 times at curved parts. The horizontal displacement of the straight parts according to the height of the reinforced soil retaining wall increased sharply, but the horizontal displacement of the curved parts were gradual. In addition, as a result of comparing the straight parts and the curved parts of the reinforced soil retaining wall at the same height, it appeared that the bulging occurred more often in the curved part than in the straight part for all cases (Figs. 11, 12, 13, 14). As a result of comparing the 


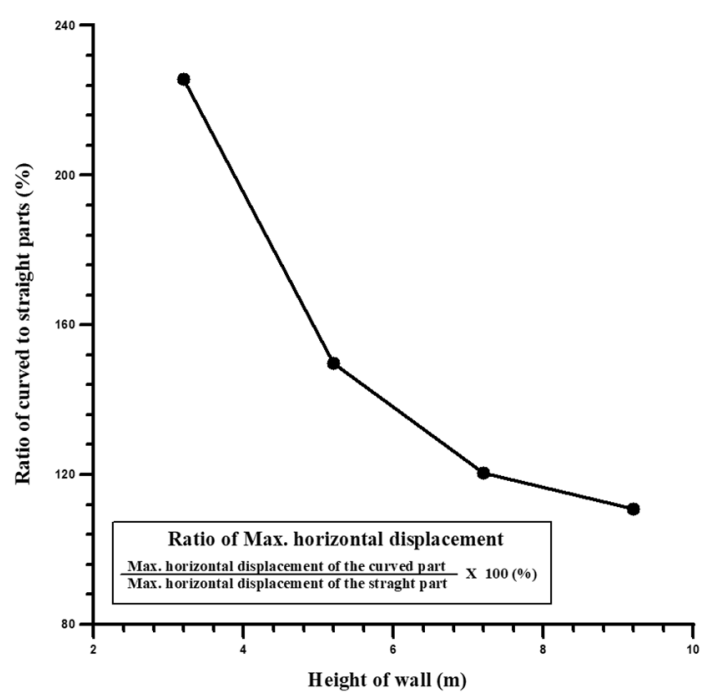

Fig. 15 Ratio of maximum horizontal displacement

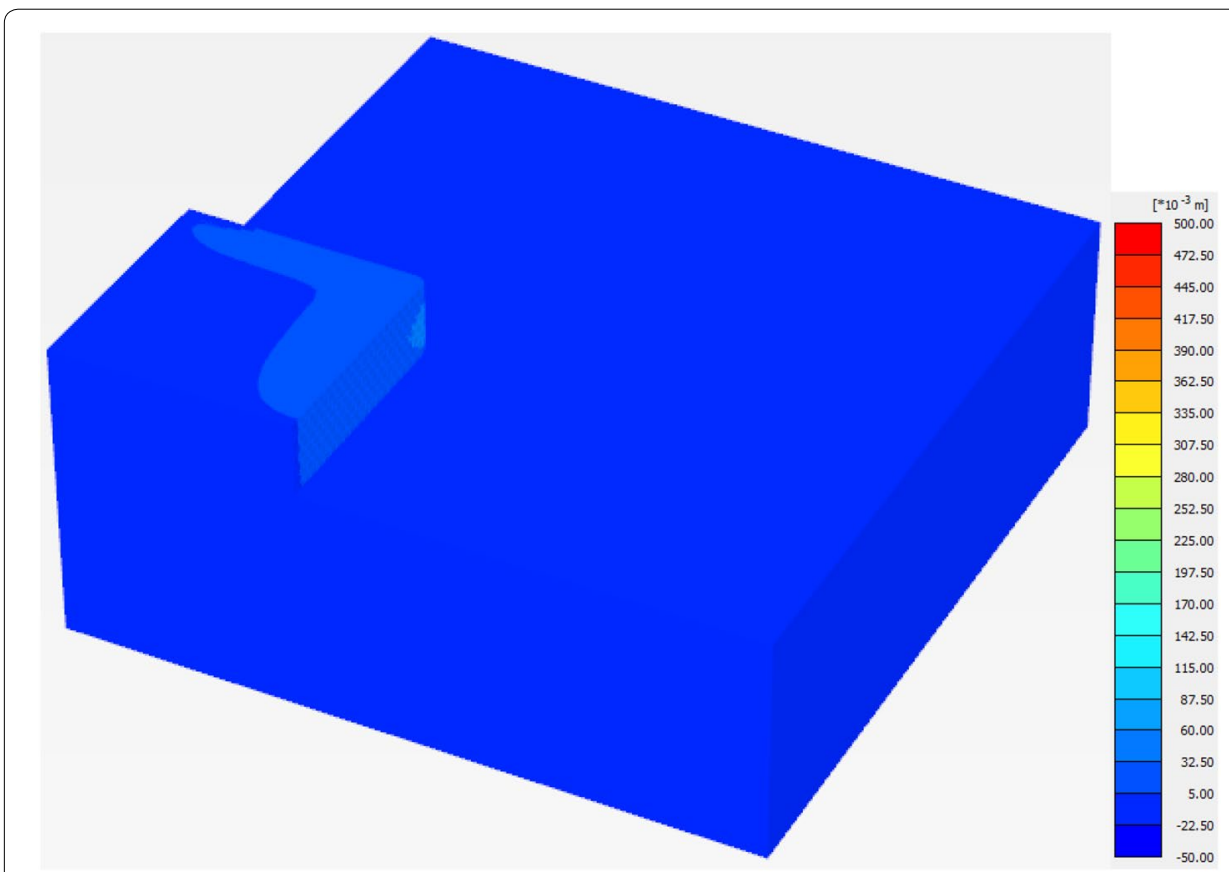

Fig. 16 Horizontal displacement contour of Case 1

maximum horizontal displacements of the straight parts and the curved parts of each case, a maximum difference of 2.26 times occurred when the height of the reinforced soil retaining wall was $3.2 \mathrm{~m}$, and as the height became higher, displacements of 1.50 , 1.20, and 1.11 times occurred (Fig. 15). Figures 16, 17, 18 and 19 show the numerical analysis result of each case of horizontal displacement. Generally, the horizontal displacements of the curved parts are larger than those of the straight parts. Therefore, the reinforcement position and the method according to the height should be 


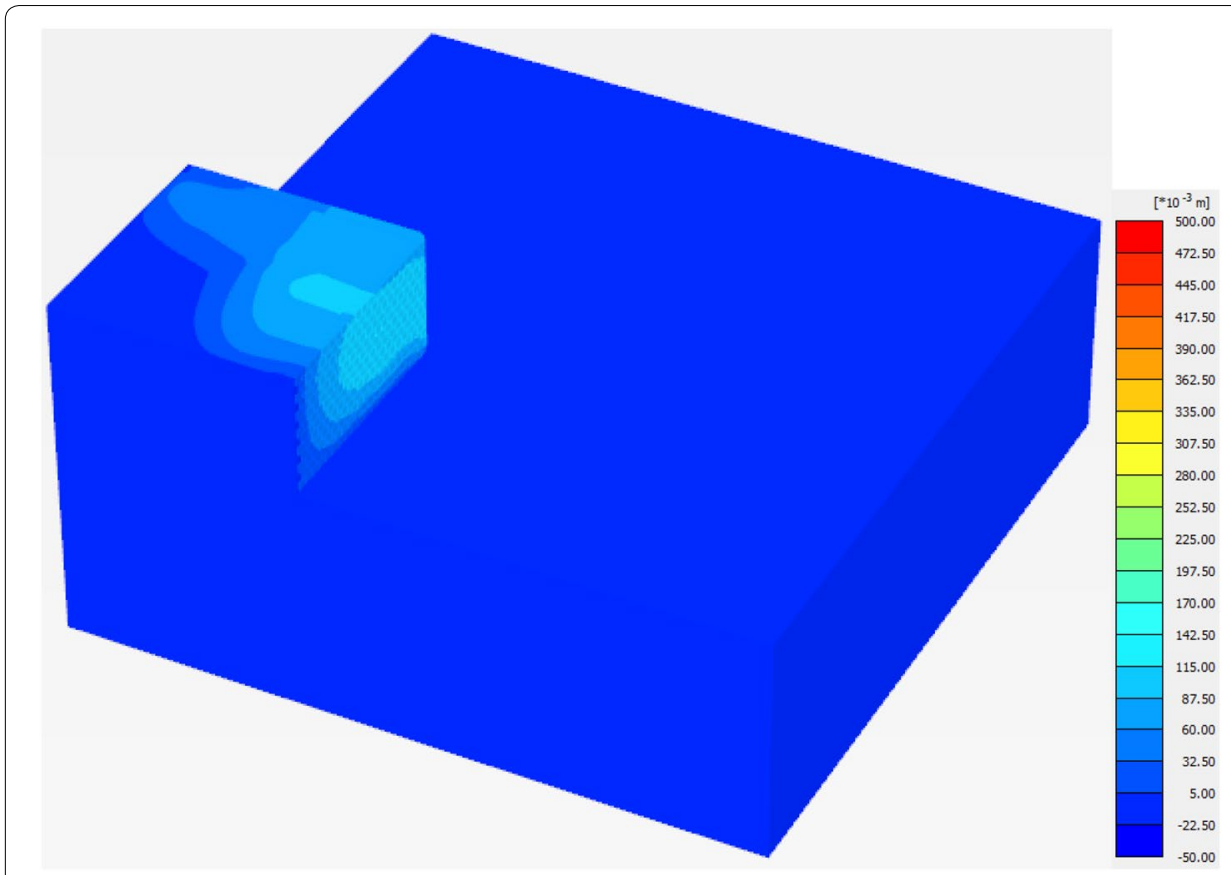

Fig. 17 Horizontal displacement contour of Case 2

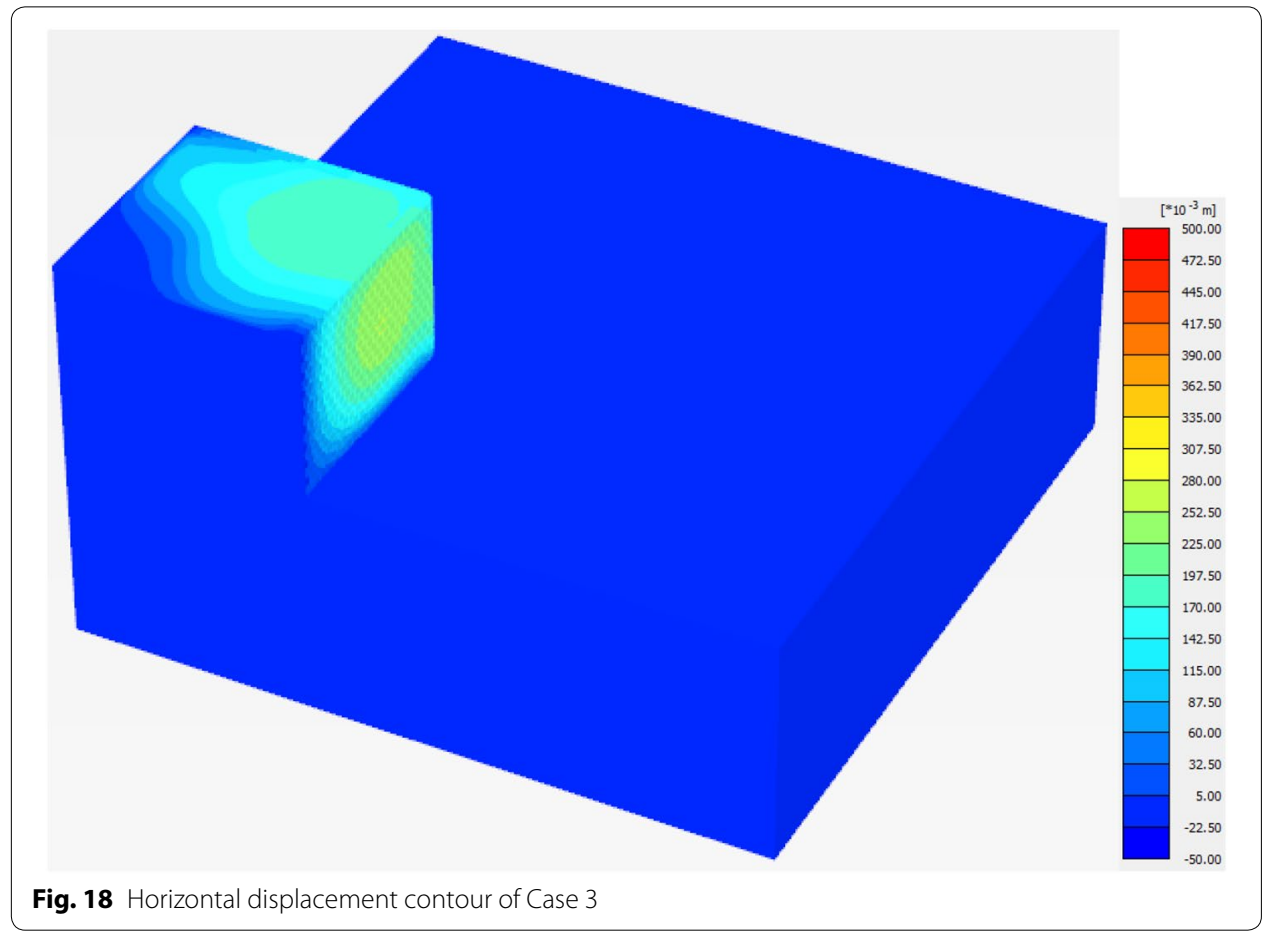

different, and it is judged that appropriate reinforcement of the bulging in the curved parts is necessary irrespective of the height. 


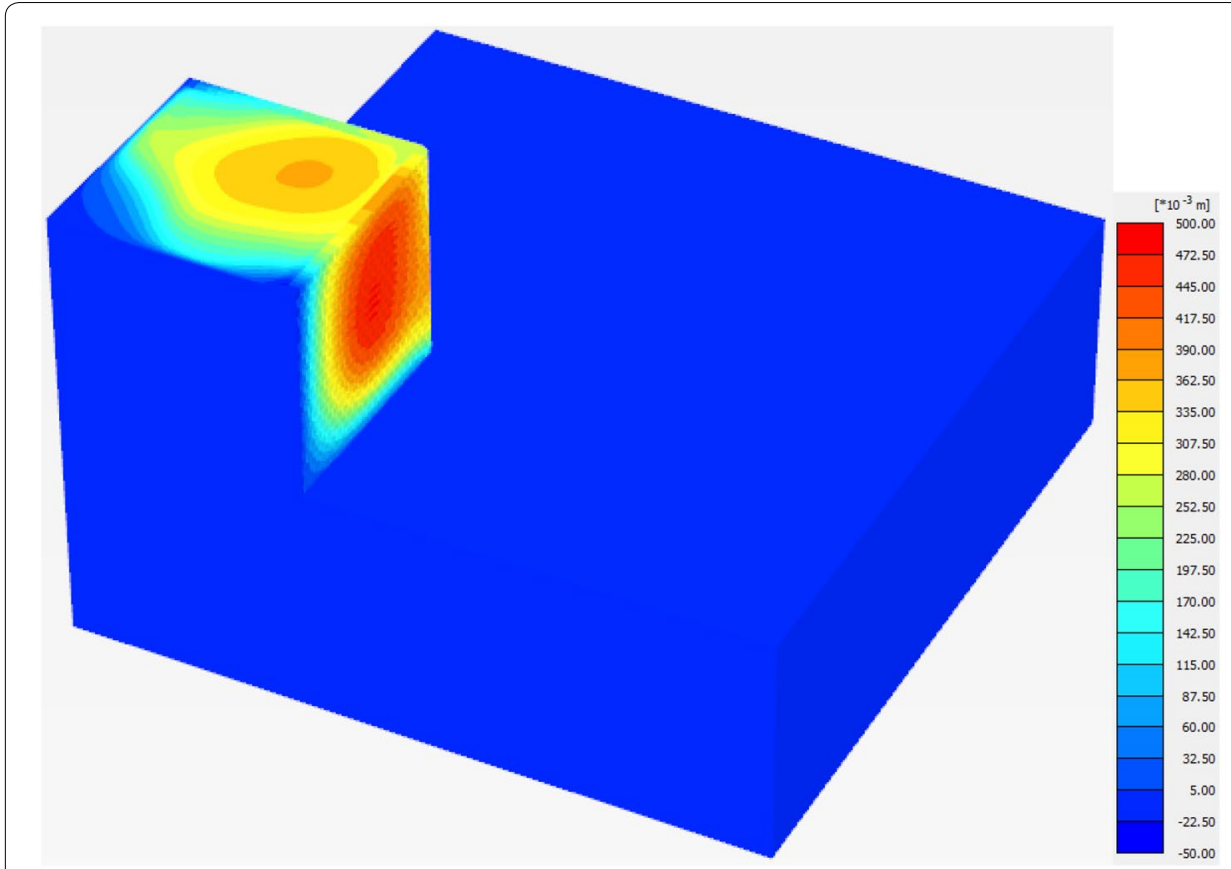

Fig. 19 Horizontal displacement contour of Case 4

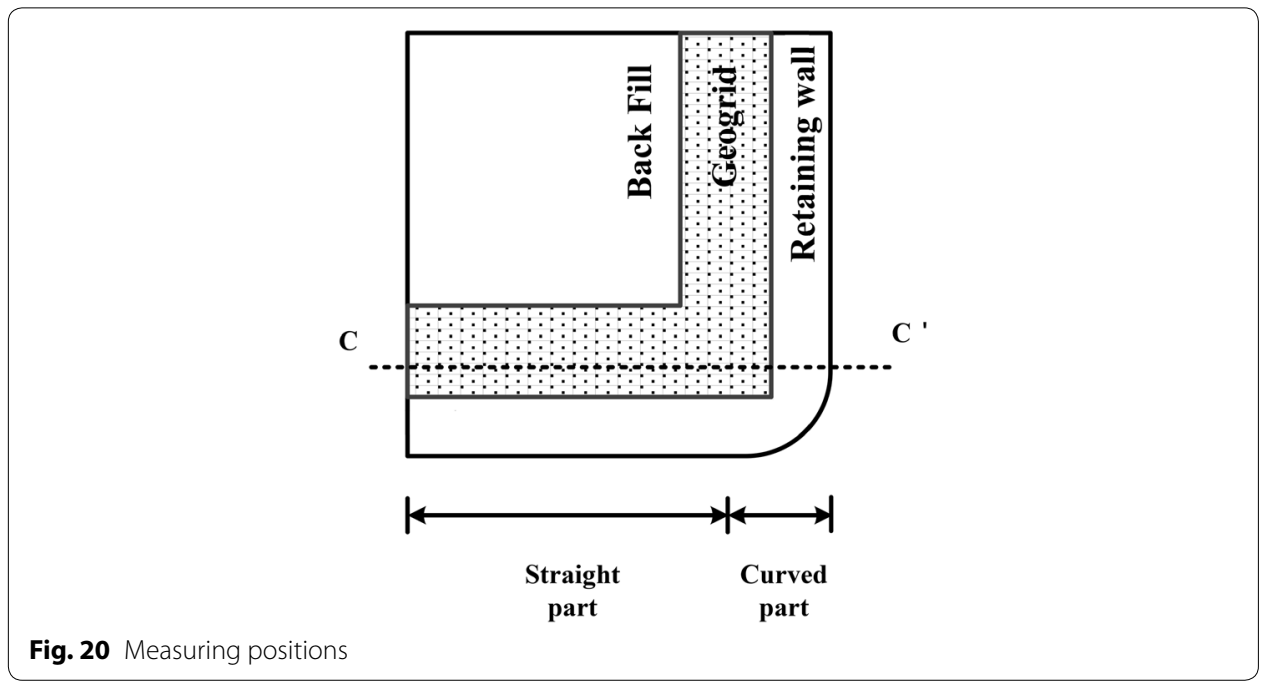

\section{Vertical displacements and ground surface settlements}

The ground surface settlements according to the height of the reinforced soil retaining wall were measured at the $\mathrm{C}-\mathrm{C}^{\prime}$ section, as shown in Fig. 20. Figure 21 shows the results of the ground surface settlements. In Case 1, the ground surface settlements of the curved and straight parts were small. However, as the height increased, the ground surface settlement amount sharply increased (Fig. 21). When the height of the reinforced soil retaining wall increased from 3.2 to $5.2 \mathrm{~m}$, the ground surface settlement amount increased by 6 times at the straight parts and by 10 times at the curved parts at the $\mathrm{D} / 2$ points (D: horizontal distance of straight and curved parts), and, as the height 


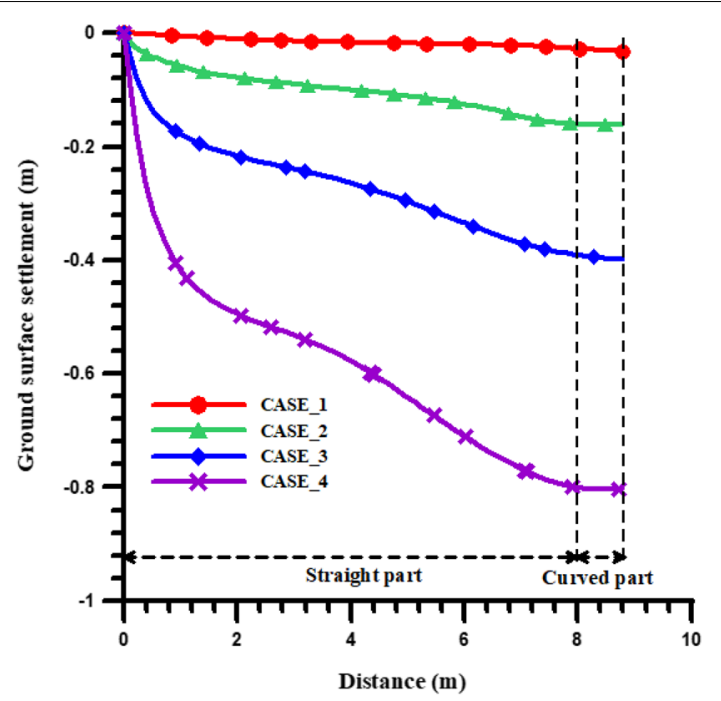

Fig. 21 Comparison of straight and curved parts for ground surface settlement

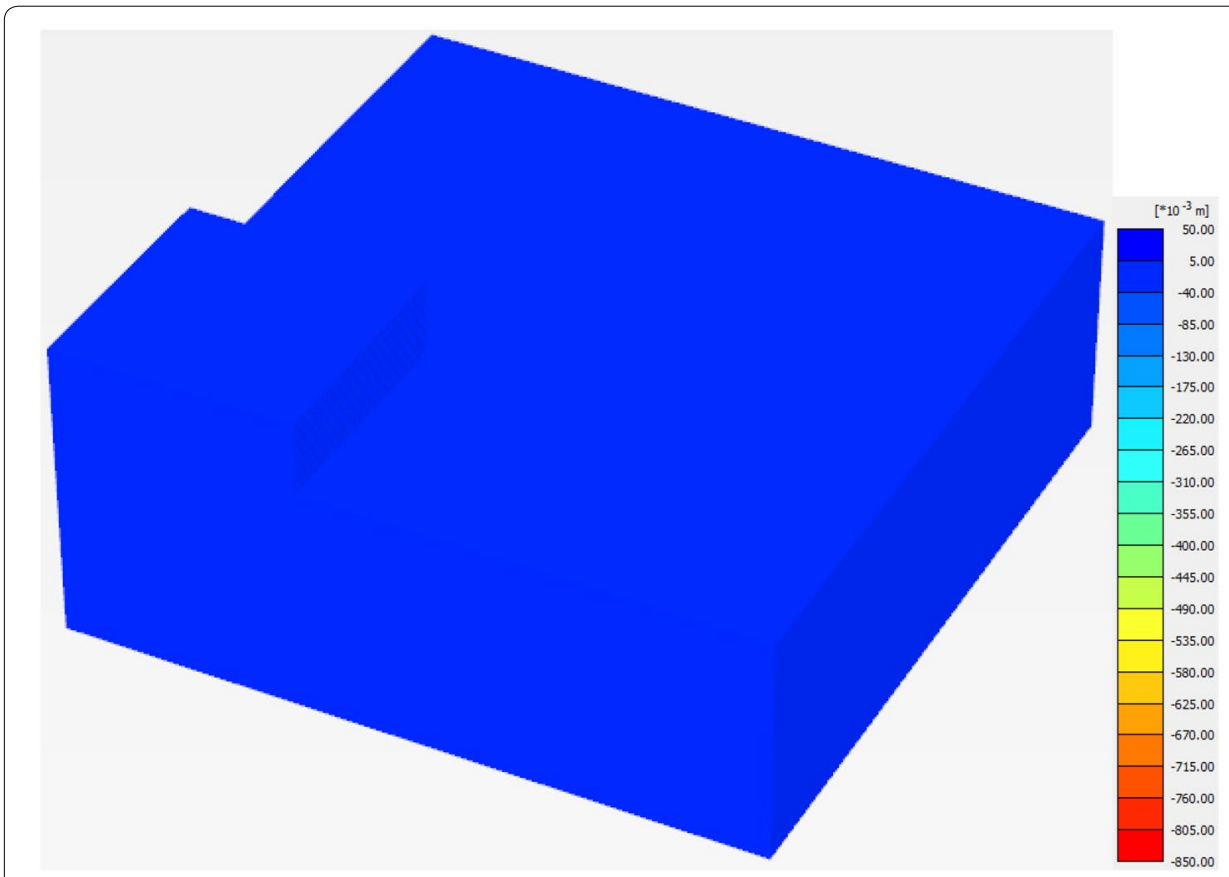

Fig. 22 Vertical displacement contour of Case 1

increased, the ground surface settlement amount increased sharply. Figures 22, 23, 24 and 25 show vertical displacement contours. The vertical displacements are concentrated from the ground surface of the curved parts. Therefore, it is judged that research on a more fragile curved part is necessary. Also, it will be necessary to take countermeasures to ground surface settlements at construction and design. 


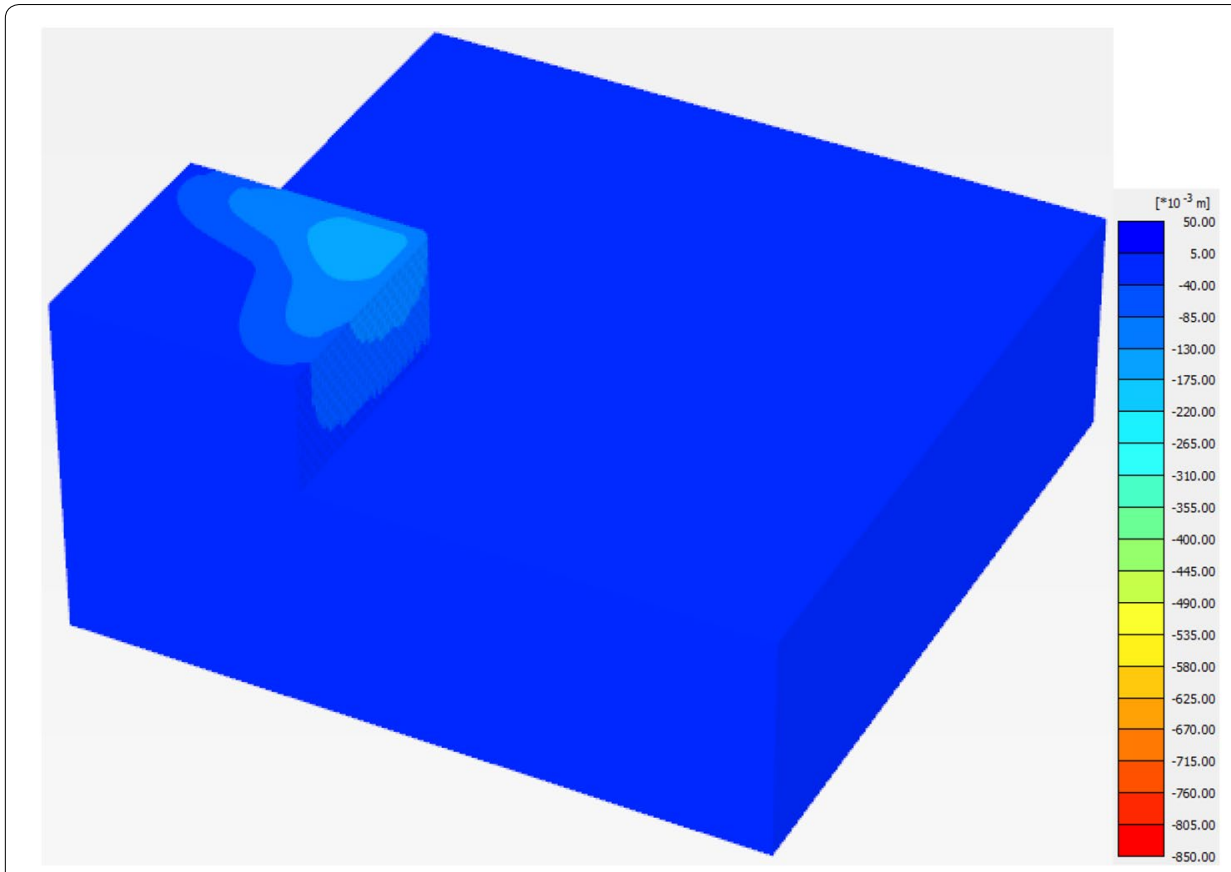

Fig. 23 Vertical displacement contour of Case 2

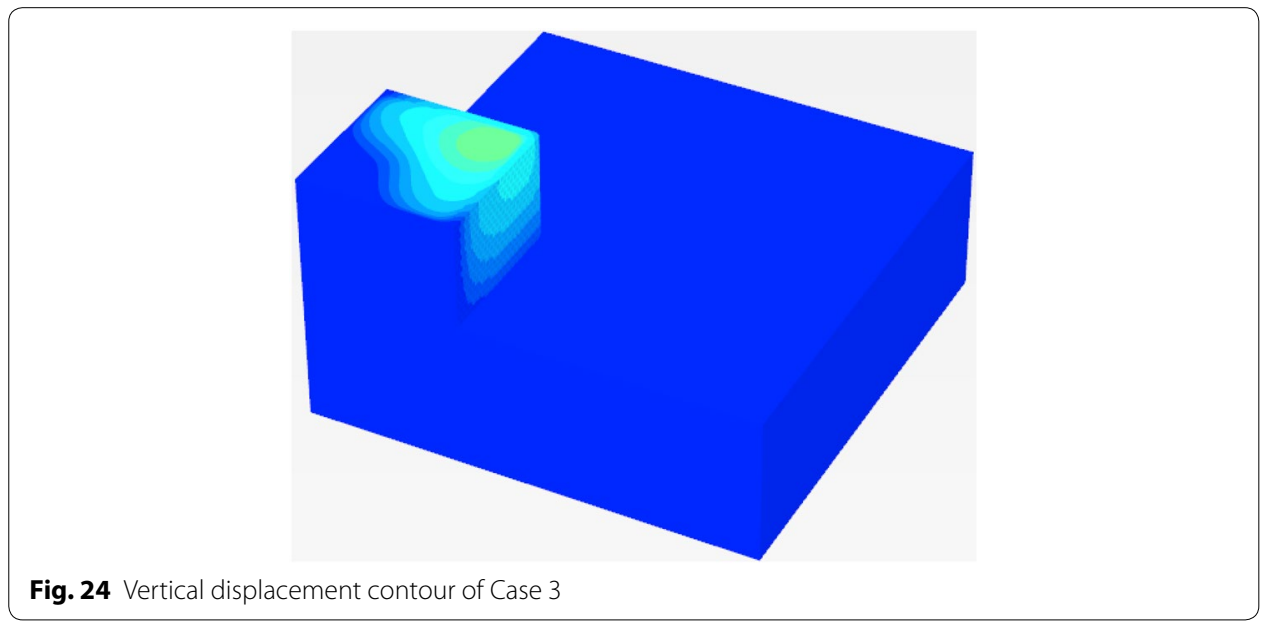

\section{Total displacement vectors}

Figures 26, 27, 28 and 29 show the total displacement vectors of the curved parts and the straight parts according to the height of the reinforcing soil retaining wall. As the height of the reinforced soil retaining wall increases, the amount of the vector increases sharply, and the vectors in the curved parts are concentrated more than in the straightline part of the wall. Therefore, it is judged that the curved parts are vulnerable, and reinforcement of curved parts is necessary. 


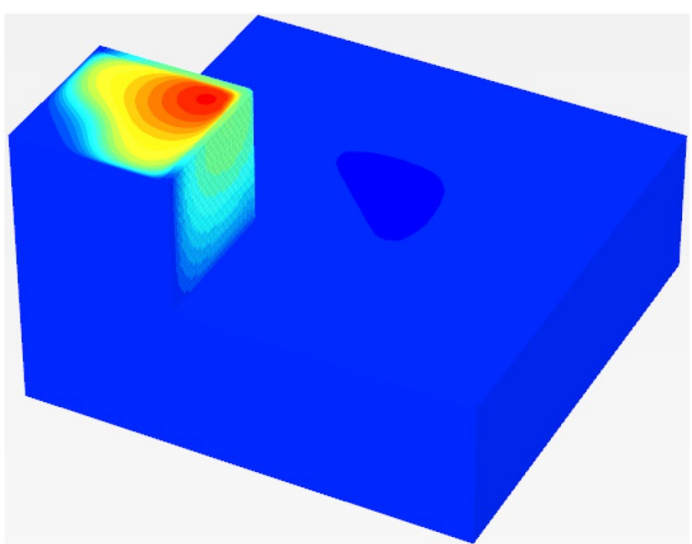

Fig. 25 Vertical displacement contour of Case 4

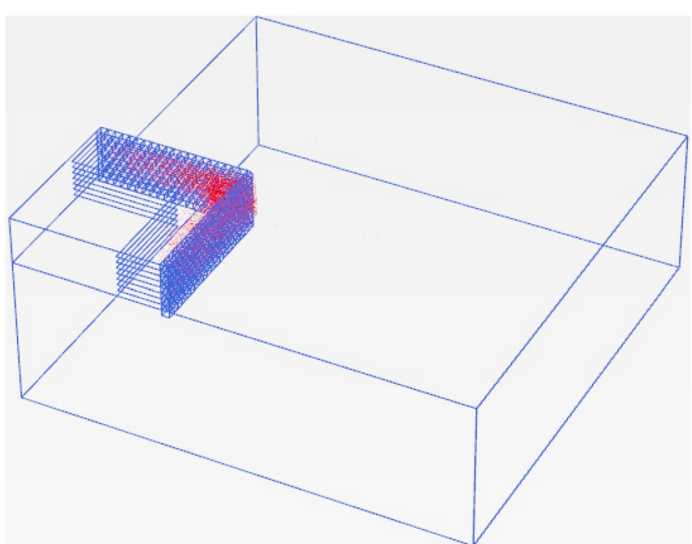

Fig. 26 Total displacement vectors of Case 1

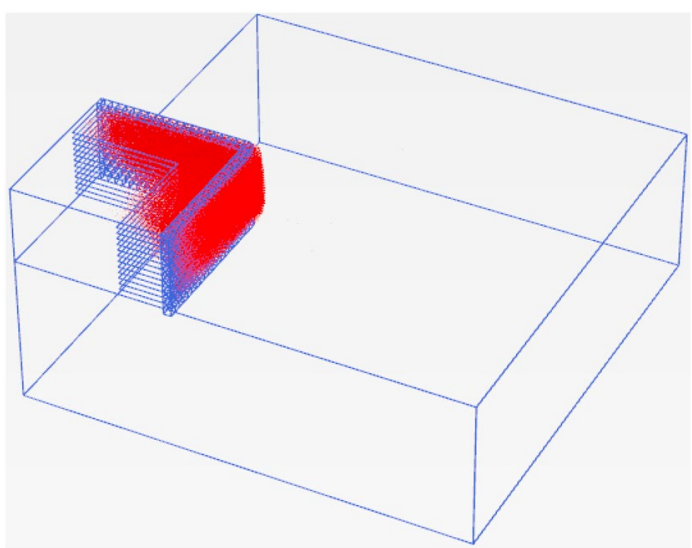

Fig. 27 Total displacement vectors of Case 2 


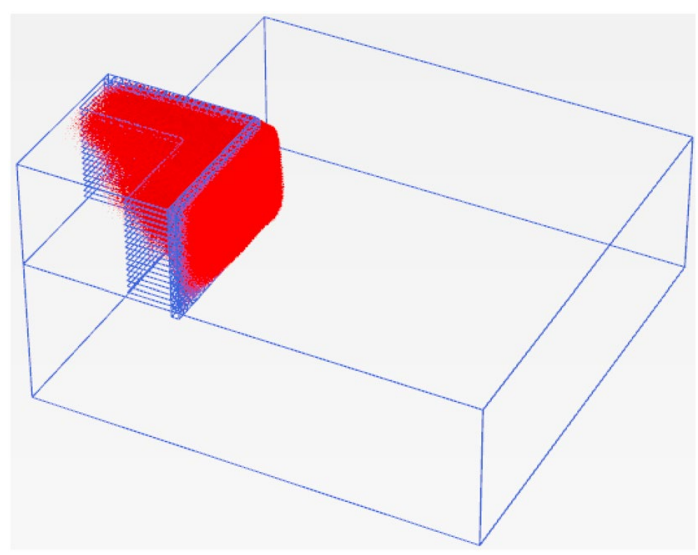

Fig. 28 Total displacement vectors of Case 3

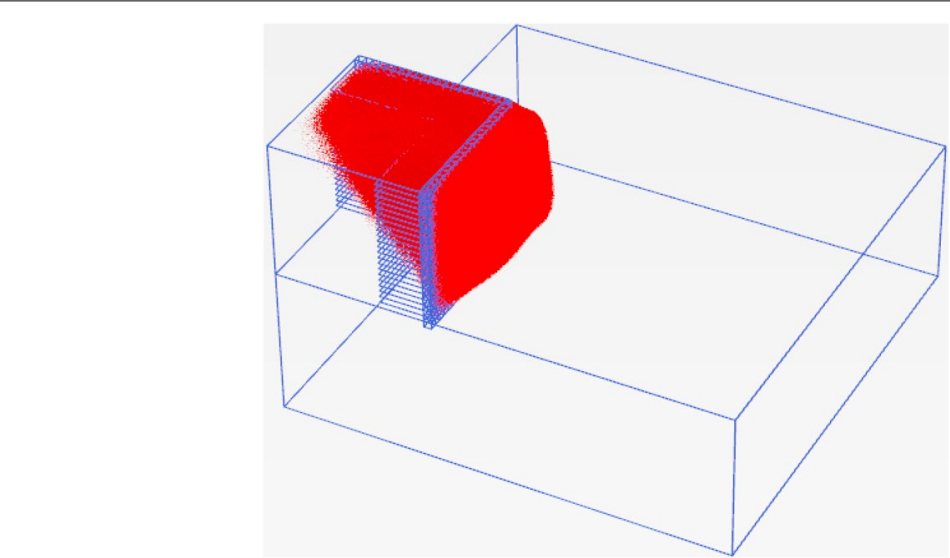

Fig. 29 Total displacement vectors of Case 4

\section{Conclusions}

In this study, the behaviours of the straight parts and the curved parts according to the height of the reinforced soil retaining wall were predicted by 3D numerical analysis, and the results are as follows:

1. Destruction of the overall reinforced soil retaining wall is displayed in bulging. The bulging becomes more prominent as the wall height increases. Also, as for the increase ratio of the horizontal displacement, the straight parts increase sharply compared with the curved parts. However, the ratio of the horizontal displacement value of the curved parts and the straight parts was 2.26 times in Case 1, and the displacements in the curved part was larger than in the straight part by 1.50, 1.20, 
and 1.11 times as the height became higher. Therefore, appropriate reinforcement according to the height and countermeasures for bulging are necessary.

2. In the results of the ground surface settlements, the settlements sharply increased according to the height of the reinforced soil retaining wall, and, when the height was $3.2 \mathrm{~m}$, the ground surface settlement amount of the curved part increased by 1.67 times compared with that of the straight part. Also, as the height increased, the value increased by $1.61,1.48$, and 1.38 times. Therefore, it is expected that countermeasures against ground surface settlements of the curved parts, which are weaker than the straight parts, at the actual construction and designing will be required.

3. Generally, the total displacement vectors of the reinforced soil retaining wall rapidly increased with the height of the reinforced soil retaining wall. The concentration of vectors at the curved part of the wall can be predicted by 3D numerical analysis. Therefore, it is judged that further research on the curved parts of the reinforced soil retaining wall is necessary. For the future, for the purpose of verification of this research, a study for comparison with the results of on-site or laboratory model tests will be planned.

\section{Authors' contribution}

All the authors contributed to analysis of this research. H-SJ conducted an existing literature study. S-MK and J-HL carried out all FEA, consequently drafted the manuscript. Y-JL participated revision of all the analyses and the manuscript. All authors read and approved the final manuscript.

\section{Author details}

'Department of Civil Engineering, Seoul National University of Science and Technology, 232 Gongneung-ro, Nowon-gu, Seoul 139-743, South Korea. ${ }^{2}$ Department of Railroad Construction and Safety Engineering, Dongyang University, 145 Dongyangdae-ro, Pnggi-eup, Gyeongsangbuk-do 36040, South Korea.

Acknowledgements

This work was supported by the National Research Foundation of Korea (NRF) Grant funded by the Korea government (MSIP) (Nos. NRF-2017R1A2B2055676 and NRF-2017R1A2B2012993).

\section{Competing interests}

The authors declare that they have no competing interests.

\section{Publisher's Note}

Springer Nature remains neutral with regard to jurisdictional claims in published maps and institutional affiliations.

Received: 16 November 2018 Accepted: 23 November 2018

Published online: 13 December 2018

\section{References}

1. Baral P, Bergado DT, Duangkhae S (2016) The use of polymeric and metallic geogrid on a full scale MSE wall/ embankment on hard foundation: a comparison of field data with simulation. Int J Geo Eng 7:1-29

2. Choi IG, Park YM (2014) Geotechnical engineering for filed practice. Goomibook, Seoul, pp 372-373

3. Das BM (2009) Principles of geotechnical engineering. Cengage Leaning, Boston, pp 302-367

4. Jung HS (2017) Comparison of behaviour of straight and curved mechanically stabilized earth walls from numerical analysis results. J Korean Geosynth Soc 16(4):83-92

5. Ki JS, Rew WH, Kim SK, Chun BS (2012) A behavior of curve section of reinforced retaining wall by model test. Korean Soc Civil Eng 32(6):249-257

6. Kwon HJ, Kim DS, Park JB, Jung SK (2011) Foundation engineering. Goomibook, Seoul, pp 320-325

7. Kwon OH, Lee KW, Cho SD (2007) Status and problems of retaining walls in Korea. In: Proceedings of Korean Geosynthetics Society 2007 Fall Conference. pp 29-37

8. Lee KM, Kong SM, Lee DY, Lee YJ (2015) Behaviour of geogrid reinforced model retaining wall in active failure state by execution of parallel movement. J Korean Geosynth Soc 14(4):1-11

9. Lee KW, Cho SD (2011) Current situation and damage cases of reinforced earth retaining wall in Korea (Part 3). Report of Korean Geosynthetics Society. Vol. 10, No. 1, Korean Geosynthetics Society. pp 8-13

10. Lee JH, Oh DW, Kong SM, Jung HS, Lee YJ (2018) Investigation of Behaviours of Wall andAdjacent Ground Considering Shape of Geosynthetic Retaining Wall. Korean Geosynthetics Society 17(1):95-109 
11. Oh DW, Kong SM, Lee JH, Hong SK, Jung HS, Lee YJ (2018) Behaviour characteristic of convex for geosynthetic retaining wall according to curvature radius. In: Proceedings of the 11 th international conference on geosynthetics. pp 16-21

12. Patki MA, Mandal JN, Dewaikar DM (2015) Computation of passive earth pressure coefficients fora vertical retaining wall with inclined cohesionless backfill. Int J Geo-Engineering. https://doi.org/10.1186/s40703-015-0004-5

13. Plaxis (2017) Plaxis 3D reference manual. Plaxis, pp 85-90

14. Sridhar R, Kumar MP (2018) Effect of number of layers on coir geotextile reinforced sand under cyclic loading. Int J Geo Eng. 9:1-14

15. Yoo CS, Jung HS, Lee SW (2004) A case study of the collapsed retaining wall. J Korean Geosynth Soc 3(2):13-21

Submit your manuscript to a SpringerOpen ${ }^{\circ}$ journal and benefit from:

- Convenient online submission

- Rigorous peer review

- Open access: articles freely available online

- High visibility within the field

- Retaining the copyright to your article

Submit your next manuscript at $\boldsymbol{\nabla}$ springeropen.com 